\title{
Environmental factors influence the detection probability in acoustic telemetry in a marine environment: results from a new setup
}

\author{
Jan Reubens 1 Pieterjan Verhelst • Inge van der Knaap • Klaas Deneudt • \\ Tom Moens $\cdot$ Francisco Hernandez
}

Received: 28 March 2017/Revised: 27 November 2017/ Accepted: 16 December 2017/Published online: 4 January 2018

(C) The Author(s) 2018. This article is an open access publication

\begin{abstract}
Acoustic telemetry is a commonly applied method to investigate the ecology of marine animals and provides a scientific basis for management and conservation. Crucial insight in animal behaviour and ecosystem functioning and dynamics is gained through acoustic receiver networks that are established in many different environments around the globe. The main limitation to this technique is the ability of the receivers to detect the signals from tagged animals present in the nearby area. To interpret acoustic data correctly, understanding influencing factors on the detection probability is critical. Therefore, range test studies are an essential part of acoustic
\end{abstract}

Electronic supplementary material The online version of this article (https://doi.org/10.1007/s10750-017-3478-7) contains supplementary material, which is available to authorized users.

Guest editors: Steven J. Degraer, Vera Van Lancker, Silvana N. R. Birchenough, Henning Reiss \& Vanessa Stelzenmüller / Interdisciplinary research in support of marine management

J. Reubens $(\varangle) \cdot$ P. Verhelst · I. van der Knaap ·

K. Deneudt · F. Hernandez

Flanders Marine Institute, Wandelaarkaai 7, 8400 Ostend,

Belgium

e-mail: Jan.reubens@vliz.be

P. Verhelst · I. van der Knaap - T. Moens

Marine Biology Research Group, Ghent University,

Krijgslaan 281, 9000 Ghent, Belgium telemetry research. Here, we investigated whether specific environmental factors (i.e. wind, currents, waves, background noise, receiver tilt and azimuth) influence the receiver detection probability for a permanent acoustic receiver network in Belgium. Noise and wind speed in relation to distance, the interaction of receiver tilt and azimuth and current speed were the most influential variables affecting the detection probability in this environment. The study indicated that there is high detection probability up to a distance of circa $200 \mathrm{~m}$. A new setup, making use of features that render valuable information for data analysis and interpretation, was tested and revealed general applicability.

Keywords Range test - Acoustic telemetry · Detection probability $\cdot$ LifeWatch project $\cdot$ North Sea

P. Verhelst

Research Institute for Nature and Forest (INBO), Havenlaan 88, 1000 Brussels, Belgium

P. Verhelst

Laboratory of Environmental Toxicology and Aquatic

Ecology, Ghent University, Jozef Plateaustraat 22,

9000 Ghent, Belgium 


\section{Introduction}

The use of acoustic telemetry has been growing a lot in recent years and acoustic receiver networks are being established around the globe in many different aquatic environments. Consequently, our understanding of the ecosystem functioning and dynamics (e.g. migration routes, spatio-temporal habitat use and movement behaviour of key species) in these environments has significantly improved in recent years. This knowledge provides a scientific basis for fisheries management (Hussey et al., 2017), species conservation, marine spatial planning (Abecasis et al., 2014; Afonso et al., 2016) and environmental impact assessment (Winter et al., 2010; Reubens et al., 2014).

In 2014, a permanent acoustic receiver network was set up in the Belgian part of the North Sea (BPNS), the Western Scheldt estuary (The Netherlands) and several rivers and canals in Belgium in the framework of a long-term European project 'LifeWatch' that aims at automated monitoring of biodiversity (http://www. lifewatch.be). The Belgian network currently consists of 177 receiver stations in the marine, estuarine and freshwater environment (Fig. 1). It is a dynamic network, and receiver stations can be added or removed according to the requirements of the projects involved (see http://www.lifewatch.be/etn/login for the most recent update of the network). Such a network of receivers allows detailed observations of animal movement and behaviour in the aquatic environment.

Although acoustic telemetry is a cost- and labourefficient method able to generate extensive datasets in a short time period, it also suffers some limitations (Hobday \& Pincock, 2011; Gjelland \& Hedger, 2013; Kessel et al., 2014) which are often less understood (Huveneers et al., 2016) or not taken into account. The most important limitation is related to the ability of a receiver to detect the signals from tagged animals in its vicinity. This so-called detection probability depends on many factors, which are linked to the physical characteristics of sound propagation through the water column (Medwin \& Clay, 1998; Gjelland \& Hedger, 2017), and can change over space and time. As a consequence, the successful application of acoustic telemetry and the correct interpretation of detection and movement data depend upon proper knowledge of the detection range (i.e. the relationship between detection probability and the distance between the receiver and tag) (Gjelland \& Hedger, 2013; Kessel et al., 2014). It is therefore important to know the environment one is working in and the factors that could influence the applicability of the technique. Therefore, before a study is initiated, the applicability of receiver arrays or networks to the questions at stake should be carefully reviewed. Thus, extensive range tests should be performed. The results of such range tests can be used to improve the setup and the design of the receiver arrays and/or to adapt the questions that can be answered (Hobday \& Pincock, 2011; Kessel et al., 2014; Stocks et al., 2014; Hayden et al., 2016; Selby et al., 2016; Steckenreuter et al., 2016).

It is well known that the detection probability will depend upon several factors related to transmission parameters (frequency, signal strength) and sound attenuation properties in the water (absorption, scattering, spreading and reflection). These attenuation properties depend upon specific characteristics of the water mass and the geomorphology of the system (e.g. temperature, salinity, substrate type, vegetation, suspended particulate matter) (Jensen et al., 1994; How \& de Lestang, 2012; Kessel et al., 2014; Gjelland \& Hedger, 2017). In addition, both anthropogenic and natural sound sources may mask the signal as the signal-to-noise ratio becomes too low (De Jong et al., 2011; Huveneers et al., 2016). The BPNS, for instance, is a shallow ocean basin with sandy sediments and strong tidal currents and winds (Baeye et al., 2011; Fettweis et al., 2012). In addition, intensive shipping traffic and offshore industry result in high anthropogenic noise generation (e.g. dredging and disposal, deepening of navigation channels, offshore wind farm construction) (Douvere et al., 2007). Both the environmental characteristics and the anthropogenic noise generation can influence the detection probability within the acoustic receiver network present in the BPNS.

Range tests can be performed in many different ways. Several options are available for the setup and duration of the test. Most used setups (a) are in situ, short-term (i.e. a couple of hours to 1 day) range tests performed during the study, and (b) use a setup with single tags at different distances from a fixed receiver. We refer to Kessel et al. (2014) for an extensive literature review on this topic. In this study, a new setup was applied, which has the advantage that it tests detection probabilities over a prolonged period of time at fixed distances, using a multitude of sentinel tags. VR2AR receivers (Vemco Ltd, Canada, Nova Scotia) 


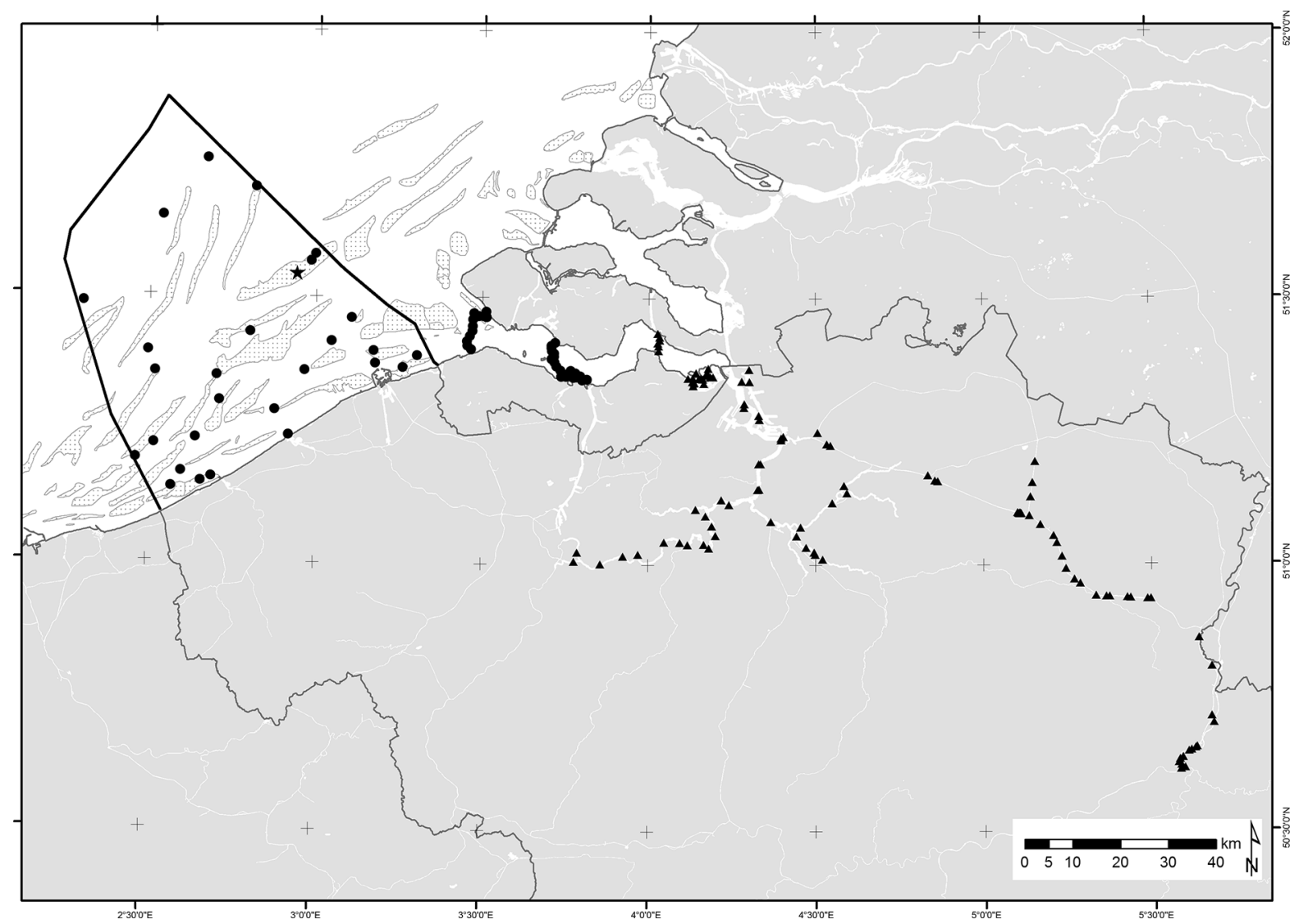

Fig. 1 The Belgian acoustic telemetry network. The dots and triangles represent the 177 receiver stations currently in operation; the dots are those stations to which the results of

were used. These receivers contain a hydrophone to record detections, a built-in transmitter which renders information on the exact transmission times, an acoustic release and several sensors which monitor tilt angle, temperature, depth and noise. The tilt sensor is the most interesting sensor in relation to range tests as it gives an indication of the receiver angle. The latter may have a profound influence on the detection probability through the angle between the incoming sound wave and the hydrophone (Berge et al., 2012), as well as through potential shadowing by the receiver body or the mooring frame.

In addition, it is expected that different meteorological and oceanographic variables influence the receivers' detection probability through time.

In this study we assess whether specific environmental factors influence the performance of acoustic receivers in a part of the Belgian receiver network (Fig. 1). More specifically, we assess (1) the influence the range test are assumed to be applicable; the black star indicates the location of the range test study. Bold black line delimits the BPNS, light-grey shading represents sand banks

of wind, currents, waves, background noise, receiver tilt, azimuth and distance on the detection probability; and (2) the average detection range in this environment. In addition, the applicability of the new setup for range tests is evaluated.

\section{Materials and methods}

Study area

The study was performed at an offshore wind farm in the BPNS (Fig. 1). It is situated on the Thornton bank, a natural sandbank about $27 \mathrm{~km}$ off the Belgian coast. The sandbanks in the BPNS are created by the strong tidal actions, which also results in a high turbidity (Otto et al., 1990). Water depth varies between 18 and $24 \mathrm{~m}$ in the area and the substratum consists of medium sand (Reubens et al., 2014). This site was 


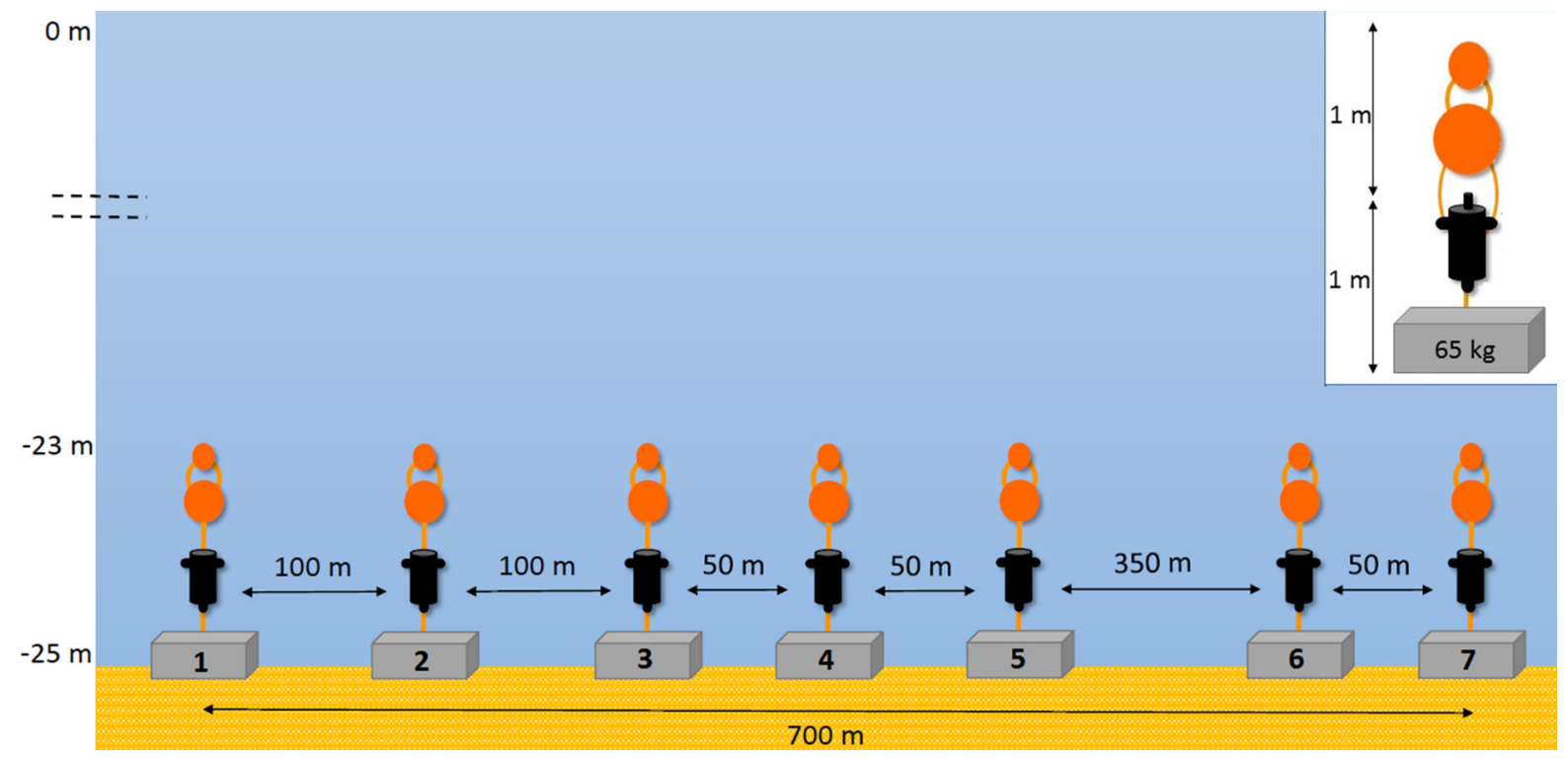

Fig. 2 Setup of the range test. Seven acoustic receivers with a built-in transmitter were used. Distances range between 0 and $700 \mathrm{~m}$, with $50 \mathrm{~m}$ increments. Tidal influence on depth is not taken into account

specifically chosen as it is closed for all types of fishing, which effectively protects the receivers against bottom disturbance due to trawling activity and thus against damage and loss. The site represents typical conditions in the BPNS (i.e. shallow depths, sandy sediments and high current velocities). Thus, although the study was performed in a small area, it is assumed that the results are applicable to most of the network's receivers in the BPNS and the entrance of the Western Scheldt (black dots in Fig. 1), except for receivers positioned in the freshwater-saltwater transition area, where boundary transitions may have a profound additional effect on detection probability.

Study design and data collection

\section{Deployment of receivers}

Seven VR2AR acoustic receivers of Vemco Ltd (Canada, Nova Scotia) were used. These receivers have a built-in transmitter (with several transmission power and delay options), sensors that measure tilt, depth, temperature and noise and an acoustic release. These features make them favourable for range tests. The receivers recognise the tag IDs from the transmitters and log the detections together with a timestamp. The receivers were deployed at fixed distances, spaced between 50 and $350 \mathrm{~m}$ from one another
(Fig. 2). This setup results in 49 distances (i.e. 7 receivers each with 7 distances), ranging from zero (logs of built-in tags) to nearly $700 \mathrm{~m}$, with approximately $50 \mathrm{~m}$ increments between the receivers and the transmitters (Fig. 2). Exact distances were based on GPS positions taken during deployment (ranging from 0 to $683 \mathrm{~m}$, see also Table 1). Transmission power of the built-in transmitters was set at $148 \mathrm{~dB}$, with a random transmission delay between 60 and $120 \mathrm{~s}$ to avoid signal collisions.

The receivers were moored on the sea bottom with a block of bluestone of approximately $65 \mathrm{~kg}$. Two hard plastic floats (280 and $180 \mathrm{~mm}$ diameter) were connected with polypropylene rope to the receiver to

Table 1 Distance matrix of real distances (m) between receivers and built-in tags

\begin{tabular}{lrrrrrrr}
\hline & R1 & R2 & \multicolumn{1}{c}{ R3 } & R4 & R5 & R6 & R7 \\
\hline T1 & 0 & 85 & 176 & 232 & 281 & 631 & 683 \\
T2 & & 0 & 97 & 150 & 199 & 548 & 600 \\
T3 & & & 0 & 59 & 106 & 455 & 507 \\
T4 & & & & 0 & 49 & 399 & 451 \\
T5 & & & & & 0 & 350 & 402 \\
T6 & & & & & & 0 & 52 \\
T7 & & & & & & & 0 \\
\hline
\end{tabular}


Table 2 Minimum and maximum value of the different environmental parameters and the tilt

An overview of the different data collection methods and stations is provided

\begin{tabular}{lllll}
\hline Variable & Method & Station & Min. value & Max. value \\
\hline Wind speed $(\mathrm{m} / \mathrm{s})$ & Measured & MOW 0 & 0.25 & 20.95 \\
Wind direction $\left(^{\circ}\right)$ & Measured & MOW 0 & 0.14 & 359 \\
Current speed $(\mathrm{m} / \mathrm{s})$ & Modelled & - & 0.13 & 0.92 \\
Current direction $\left(^{\circ}\right)$ & Modelled & - & 0.07 & 359 \\
Wave Height $(\mathrm{cm})$ & Measured & Westhinder & 30 & 254 \\
Tilt $\left(^{\circ}\right)$ & Measured & Built-in sensor & 0 & 25 \\
Noise $(\mathrm{mV})$ & Measured & Built-in sensor & 105 & 903 \\
\hline
\end{tabular}

keep it in upright position (hydrophones pointing to the surface). Floats were positioned ca $1 \mathrm{~m}$ above the hydrophone to ensure that the detection field of the hydrophones was not blocked. No surface floats were used to avoid ship collisions. For detailed information on mooring design, see Vemco (2016a).

\section{Monitoring environmental parameters}

Several oceanographic (current speed, current direction and wave height) and meteorological (wind speed and wind direction) parameters were measured during the study. Wind speed and wind direction data were obtained from 'Meetnet Vlaamse Banken', from station MOW $0\left(51.33^{\circ} \mathrm{N}, 3.22^{\circ} \mathrm{E}\right)$ at $31 \mathrm{~km}$ from the study area. Wave height was also obtained by 'Meetnet Vlaamse Banken' but from station Westhin$\operatorname{der}\left(51.38^{\circ} \mathrm{N}, 2.44^{\circ} \mathrm{E}\right)$ at $39 \mathrm{~km}$ distance, as these data were not available at MOW 0 . Current data were calculated from a 2D hydrodynamic model from the Operational Directorate Nature of the Royal Belgian Institute for Natural Sciences. The modelled currents are based upon astronomical tides and meteorological influences (i.e. wind and atmospheric pressure). In addition to these measured and modelled environmental parameters, the tilt measurements from the VR2AR built-in sensor were used as well. Although tilt is not an environmental parameter, it may potentially influence detection probability if this is not perfectly omnidirectional, and was therefore taken into account. This parameter was logged for the duration of the study with a 10-min interval.

In addition, we calculated the azimuth (i.e. the angle) between the transmitter-to-receiver bearing and the current direction, scaled to $180^{\circ}$. This parameter provides additional information related to the angle between the receiver and the incoming signal, which may reveal, e.g. shadowing effects caused by the receiver body. An azimuth of $0^{\circ}$ indicates that transmitter-to-receiver bearing and current direction have the same bearing, while at $180^{\circ}$ they have a completely opposite direction.

Temperature, salinity, depth and sediment type were not taken into account for the modelling, as receivers and tags were all present in the same environment and at very similar depths. No thermoclines nor haloclines are present in the area as the water column is well mixed.

The study ran for 22 days (from 18-02-2016 to 10-03-2016). This period encompassed varying environmental conditions (Table 2), making it possible to assess the influence of the different parameters on receiver performance and detection probability. Temperature varied between 6.5 and $8.0^{\circ} \mathrm{C}$ and average water depth was $23 \mathrm{~m}$. Wind speed varied between 0.25 and $21 \mathrm{~m} / \mathrm{s}$, while current speed ranged between 0.13 and $0.92 \mathrm{~m} / \mathrm{s}$. Wave height varied between 0.30 and $2.54 \mathrm{~m}$, tilt between 0 and $25^{\circ}$.

The study was performed in winter time, allowing for harsh environmental conditions (i.e. strong winds and high waves).

Data analysis

At the end of the study, data were downloaded from the receivers and were uploaded into the European Tracking Network database (http://www.lifewatch.be/ etn). A dataset, containing the 442,856 transmissions from the built-in transmitters detected by the seven receivers, was created.

Detection data were binned per half hour (as the weakest resolution of the environmental data was per half hour) for each receiver-tag combination (hereafter referred to as events), and linked to the environmental parameters for the same time period. All events in which no detections were encountered were also 
added to the data frame, as we were not only interested in presences, but also absences. This resulted in 49,098 distinct events. As receiver clocks are sensitive to time drift, detection data were accounted for possible time drift using the linear time drift correction available in the VUE software of Vemco Ltd. It was assured that PC clock time was correct at the moment of initialisation of the receiver and upload of the data.

The effects of the environmental variables on the detection probability were assessed.

First, the data were checked for outliers (defined as data points below Q1 $-1.5 \times \mathrm{IQR}$ or above $\mathrm{Q} 3+1.5 \times \mathrm{IQR})$ followed by a collinearity analysis (Zuur et al., 2010). If correlations were found, one of the covariates was excluded from the analysis (Dormann et al., 2013).

To determine which environmental variables contributed to the detection probability, a generalised linear model was applied. The covariates were scaled by applying a $z$-transformation: scaled $x=\frac{(x-\operatorname{mean}(x))}{\operatorname{sd}(x)}$. The model was tested for overdispersion and zeroinflation. Overdispersion was tested using the Vuong test from the pscl package in R (R Core Team, 2016). As the Vuong test revealed that the negative binomial distribution performed better than the Poisson distribution, it could be assumed that overdispersion did occur and thus the negative binomial distribution should be used. A histogram showing the number of detections per event revealed that the data were zeroinflated. Due to the random transmission delay of the tags, the number of transmissions a tag emitted per half hour time bin differed through time. To account for this, an offset was used in the model (Zuur et al., 2009). The offset was defined as the logarithm of the number of transmissions sent out by the built-in tag per event. Based on the result from the above tests, it was decided to use a zero-inflated negative binomial (ZINB) distribution with an offset for the model development. For more details on ZINB models we refer to Zuur et al. (2009). The package pscl of the $\mathrm{R}$ environment (R Core Team, 2016) was used. Based on Forstmeier \& Schielzeth (2011) and Hegyi \& Garamszegi (2011) it was decided to work with the full model.

In addition, to estimate the average detection range within our study site, the detection probability per distance was calculated for the half hour time bins. This probability was calculated as the number of transmissions received, divided by the number of transmissions sent out.

\section{Results}

Variables influencing detection probability

The large temporal variation in detection rate (Fig. 3) indicates that environmental factors influence the detection probability. Under favourable oceanographic conditions, transmissions can be received much further (even beyond $400 \mathrm{~m}$ ). On the other hand, in unfavourable conditions, transmissions can be missed even at very close distances.

Collinearity analysis revealed a high correlation between wave height and wind speed (0.72). We decided to remove wave height since wind information consists of two components (direction and speed), each of which can be informative. The model revealed that several environmental parameters influence the detection probability. The interactions of noise and distance, and of wind and distance contributed most, followed by the interaction between tilt and azimuth, and current speed (Table 3). It should be kept in mind that there still is a lot of unexplained variation. At close distances, the detection probability is not much influenced by noise or wind. However, at larger distances, noise and wind negatively influenced the detection probability (Fig. 4, Supplementary Material Fig. 2). The influence of the azimuth depended upon the receiver tilt. At no or low receiver inclination, the detection probability increased with increasing azimuth; while at higher receiver inclination, azimuth negatively influenced the probability. The detection probability decreased only slightly between minimum and maximum current speed (Fig. 4), hence the current speed only has a limited impact on the detection probability.

\section{Detection range}

Figures 3 and 5 reveal that the average detection rates are high (i.e. above 70\%) until a distance of ca. $200 \mathrm{~m}$, whereafter they quickly drop to (near) zero at a distance of $350 \mathrm{~m}$. These results indicate that there is a limited detection range within this dynamic environment. However, there is considerable temporal 


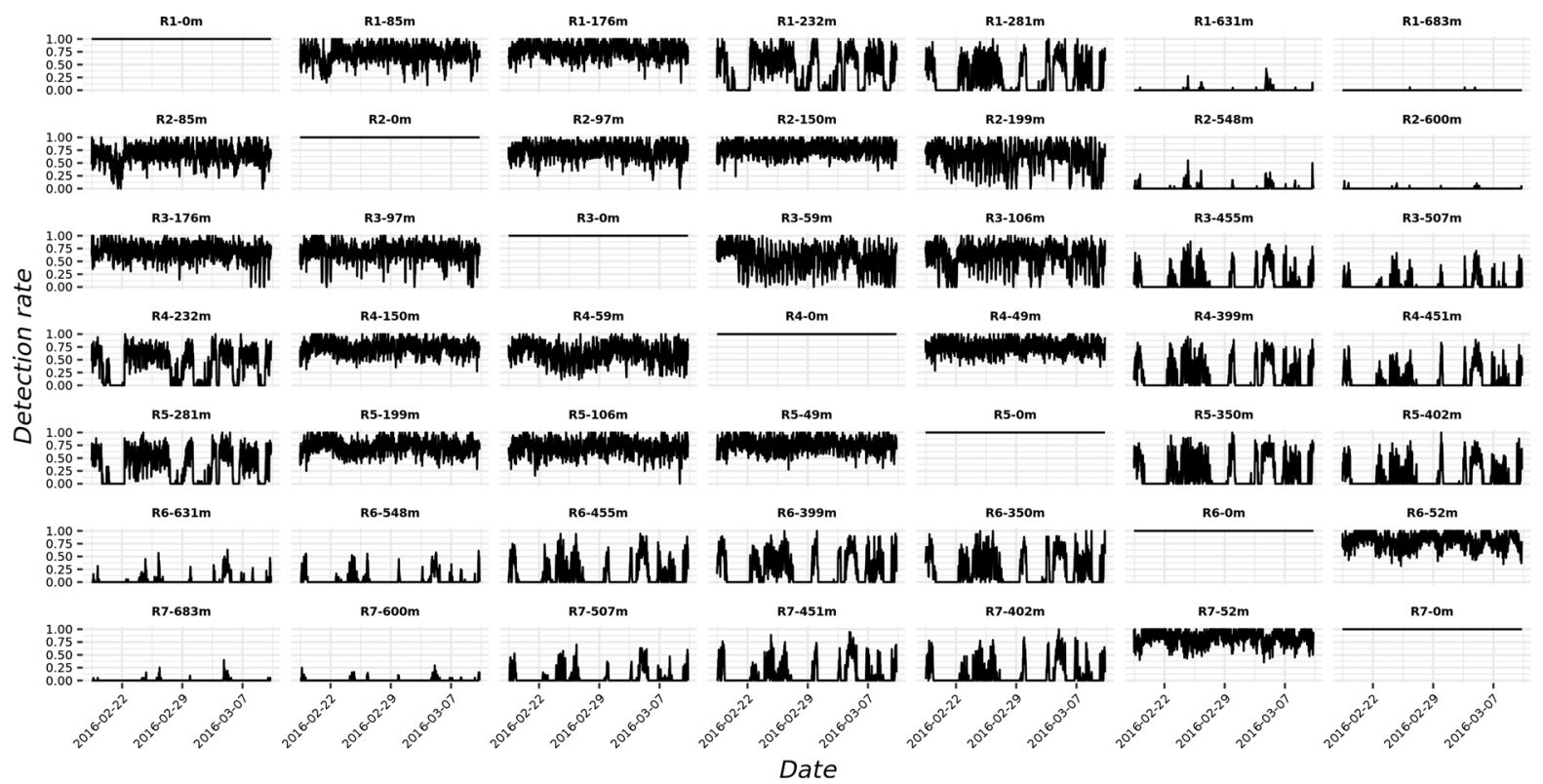

Fig. 3 Detection rate for all distances for the seven groups for the duration of the study. Each group represents the detections over time of one receiver linked to seven transmitters

variation in detection probability, and thus in detection range.

\section{Discussion}

Variables influencing detection probability

Our results demonstrated that detection probability is not static and can change considerably over time. It was mainly influenced by noise and wind speed in relation to distance, the interaction between tilt and azimuth, and current speed, which is in agreement with Gjelland \& Hedger (2013) and Huveneers et al. (2016). In contrast, Stocks et al. (2014) listed wave height as the principal factor affecting detection range. However, wave height was highly correlated with wind speed, hence our study does not contradict the results of Stocks et al. (2014).

The influence of wind can be attributed to both the noise generation itself and to the air bubbles that are mixed into the water column (Gjelland \& Hedger, 2013). Scattering of signals in strongly wind-influenced surface layers will, due to air bubbles (Medwin \& Clay, 1998) and multipath (Dol et al., 2013), not only increase the sound attenuation in these layers, but also contribute to increased background noise levels, even at larger depth.

The interaction effects of noise with distance, and of wind with distance can be explained by the signalto-noise ratio (SNR). At close distances, the SNR is still high, hence the transmitted signal strength dominates over the ambient noise (including windgenerated noise) present in the environment. At higher distances, the transmitted signal has already lost part of its strength due to attenuation and interference, and therefore negatively influences the SNR (VEMCO, 2015).

The present study was performed in an offshore wind farm, and although it is expected that ambient noise in this area is lower than in the surrounding environment because no shipping or industrial activities take place here, noise still significantly influenced the detection probability. Both anthropogenic and natural sound sources may mask the transmission signal (De Jong et al., 2011; Huveneers et al., 2016; Gjelland \& Hedger, 2017), and it is difficult to attribute the impact to a specific sound source. As the sound sources, and thus the SNR, strongly vary in both spatial and temporal context, the influence of noise on the detection probability may strongly differ between receiver stations in the Belgian network. 
The influence of currents, on the other hand, can be attributed to both flow noise and tilt angle of the hydrophone. Flow noise refers to changes in pressure and the creation of eddies around the hydrophone under high flow conditions, and can be caused by movement of the hydrophone in the water column (Martin et al., 2013). In addition, the hydrophone can also receive strumming noise from ropes under tension. As flow noise generally occurs below $1 \mathrm{kHz}$ (Martin et al., 2013), this does not cause problems for acoustic receivers. However, the eddy creation may cause sound attenuation. The tilt angle of the hydrophone presumably better explains the variation in the detection probability than current in itself (Supplementary Material Fig. 3). The higher the current velocity, the higher the tilt angle becomes. If the tilt angle becomes too high, the hydrophone no
Fig. 4 Summary of the partial effects of the environmental parameters on the detection probability. For interaction effects, the minimum medium and maximum value for distance and tilt are shown. Dashed lines indicate the $95 \%$ confidence intervals

longer has an unobstructed view and shadow zones are created (VEMCO, 2016a), which can adversely affect the detection probability. However, this is also influenced by the azimuth as the interaction effect between tilt and azimuth indicated. The azimuth is defined as the angle between the transmitter-to-receiver bearing and the current direction, which changes over time. At some moments in time, the receiver may be tilted towards the focus transmitter, resulting in a higher detection probability. With changes in the current direction, the receiver is tilted away from the
Table 3 Negative binomial model summary
*Represents the interaction effect

\begin{tabular}{|c|c|c|c|c|}
\hline & Estimate & Std. error & $z$ value & $P$ value \\
\hline \multicolumn{5}{|c|}{ Count part: Negbin with log link } \\
\hline (Intercept) & -0.75 & 0.00 & -211.95 & $<0.001$ \\
\hline Wind speed & -0.04 & 0.00 & -10.05 & $<0.001$ \\
\hline Distance & -0.57 & 0.00 & -149.79 & $<0.001$ \\
\hline Wind direction & -0.01 & 0.00 & -4.07 & $<0.001$ \\
\hline Tilt & -0.02 & 0.00 & -7.21 & $<0.001$ \\
\hline Azimuth & 0.00 & 0.00 & -0.81 & 0.42 \\
\hline Noise & -0.10 & 0.00 & -32.83 & $<0.001$ \\
\hline Current speed & -0.01 & 0.00 & -4.25 & $<0.001$ \\
\hline Current direction & 0.00 & 0.00 & 0.64 & 0.52 \\
\hline Wind speed $*$ distance & -0.04 & 0.00 & -10.69 & $<0.001$ \\
\hline Tilt * azimuth & -0.01 & 0.00 & -7.14 & $<0.001$ \\
\hline Noise $*$ distance & -0.08 & 0.00 & -27.68 & $<0.001$ \\
\hline $\log ($ theta $)$ & 13.63 & 9.54 & 1.43 & 0.15 \\
\hline \multicolumn{5}{|c|}{ Inflated part: Binomial with logit link } \\
\hline (Intercept) & -5.15 & 0.04 & -129.81 & $<0.001$ \\
\hline Wind speed & 2.46 & 0.04 & 59.44 & $<0.001$ \\
\hline Distance & 5.58 & 0.07 & 80.45 & $<0.001$ \\
\hline Wind direction & -0.04 & 0.02 & -1.90 & 0.057 \\
\hline Tilt & 0.34 & 0.03 & 10.51 & $<0.001$ \\
\hline Azimuth & -0.03 & 0.03 & -0.99 & 0.32 \\
\hline Noise & 0.29 & 0.03 & 8.31 & $<0.001$ \\
\hline Current speed & 0.23 & 0.03 & 7.72 & $<0.001$ \\
\hline Current direction & 0.03 & 0.02 & 1.44 & 0.15 \\
\hline Wind speed $*$ distance & 1.24 & 0.04 & 29.17 & $<0.001$ \\
\hline Tilt $*$ Azimuth & -0.05 & 0.04 & -1.33 & 0.18 \\
\hline Noise $*$ distance & 0.47 & 0.04 & 12.02 & $<0.001$ \\
\hline
\end{tabular}



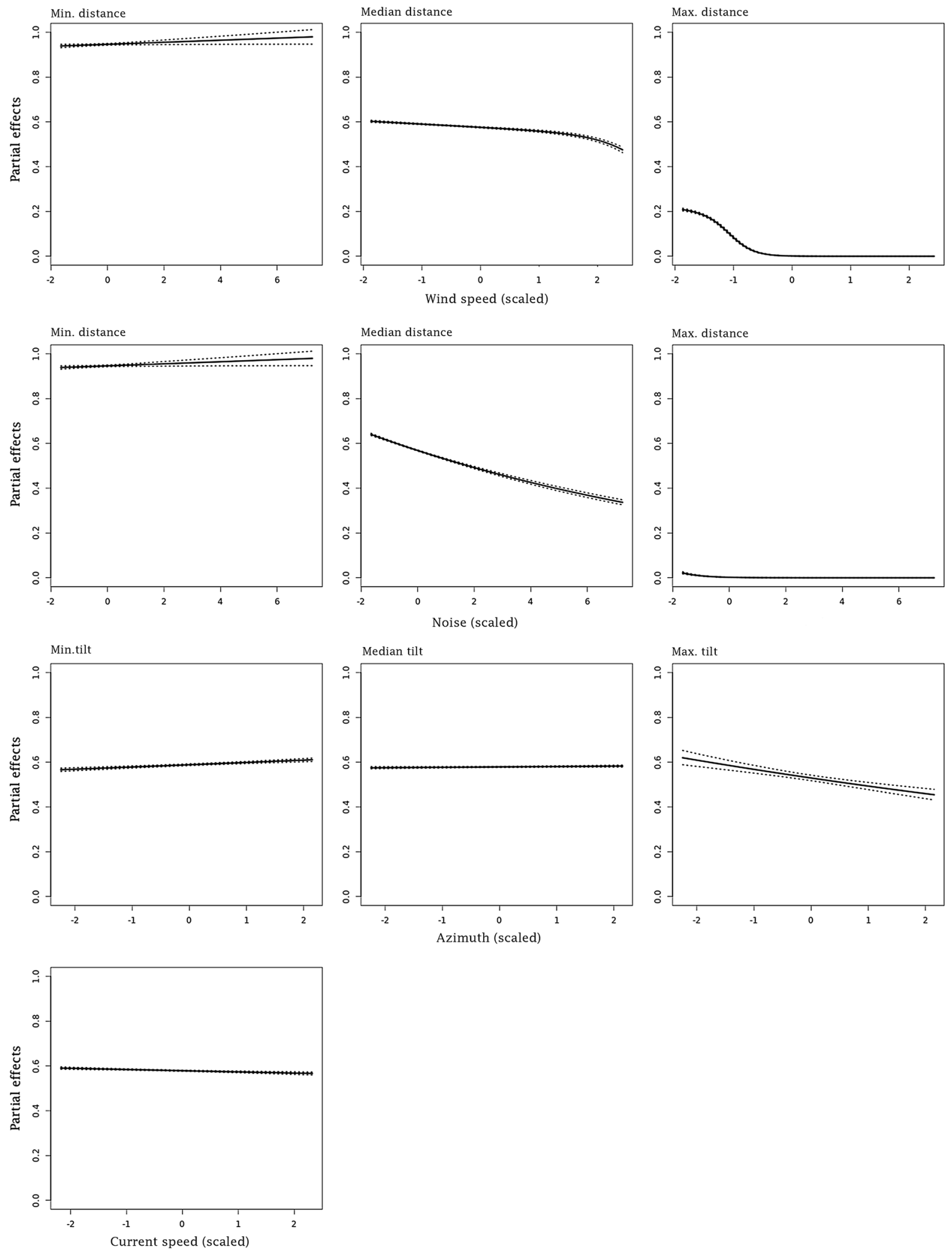


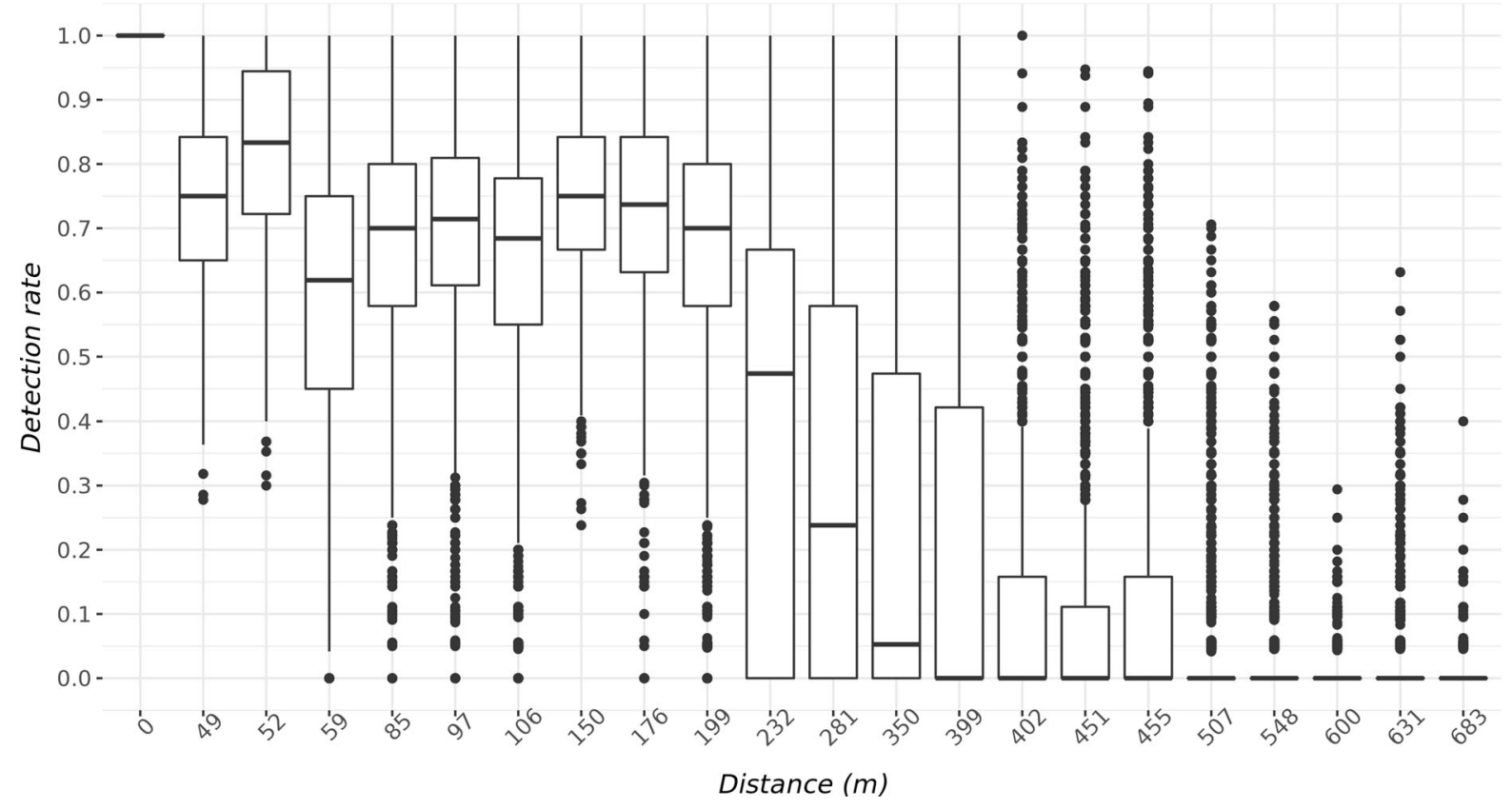

Fig. 5 Boxplots of detection rate in relation to the distance between receiver and transmitter. Dots represent outliers

transmitter, causing reduced detection probability due to shadowing.

In addition, the present results revealed that the detection probability does not decline linearly, but shows some inconsistencies at close distances. Although the receiver-transmitter distance was within the same range between 49 and $59 \mathrm{~m}$, the detection probability differed considerably. This might be related to small local differences in the environment, as mentioned earlier. However, it can also be related to close-proximity detection interference (CPDI) or tag code collision. As stated by Kessel et al. (2015) and Gjelland \& Hedger (2017), CPDI occurs when reflective barriers (e.g. water surface, air bubbles) result in multiple pathways from transmitter to receiver. As these multipath signals have the same frequency, they contribute to the background noise. Code collision is a function of the number of transmitters within range of the receiver, the signal duration and signal delay (Binder et al., 2016). At larger distances there is a reduction in cod collisions as transmissions are attenuated.

Besides environmental variables, sediment characteristics and topography, also the mooring design, the transmission characteristics of the tags, the transmitter attachment on the fish and the configuration of the receivers can all influence the detection probability (Clements et al., 2005; Heupel et al., 2006; Simpfendorfer et al., 2008; Hobday \& Pincock, 2011; Dance et al., 2016). For this range test, transmission power output was set at $148 \mathrm{~dB}$, and the receivers were moored near the bottom with the hydrophone pointing in an upward direction. Different setups or tag specifications will undoubtedly affect the results. Many of the receivers deployed in the BPNS and the Western Scheldt are moored near the surface (using navigation buoys) with the hydrophone pointing downward. As wind action significantly influences detection probability, it can be expected that receivers near the surface will be more negatively influenced by wind than receivers near the bottom. On the other hand, the range test was performed in winter, when more extreme weather events such as storms and high waves occur. In the whole of 2016, the maximum wind speed was $25 \mathrm{~m} / \mathrm{s}$ at MOW 0 , with a peak of $21 \mathrm{~m} / \mathrm{s}$ during our test period, while the largest wave height measured in 2016 was $3.8 \mathrm{~m}$, compared to $2.54 \mathrm{~m}$ during our test period. High wind speeds and wave heights were mainly measured in quarter 1 of 2016. As a result, most of the year, detection range may be higher than what we found in this study. 
Detection range

The present study demonstrates that there is a good detection probability up to $200 \mathrm{~m}$, but it quickly reduces beyond this distance. This detection range is in the range of previous reports, which encompass both higher (Hobday \& Pincock, 2011; Huveneers et al., 2016) and similar range values (Welsh et al., 2012; Cagua et al., 2013, Stocks et al., 2014). Some other publications have reported a broad range of distances within the same study (How \& de Lestang, 2012; Cagua et al., 2013; Gjelland \& Hedger, 2013). Although the detection ranges differ extensively between the cited studies, they all concluded that detection range strongly depends upon meteorological and oceanographic environmental variables, on sediment characteristics and on the environment's topographic complexity factors which all influence sound propagation in water. As environmental conditions and topography differ largely between areas, detection ranges will do so as well. Even in environments that look comparable at first sight, small local differences can have large effects on the detection probabilities and thus also on the detection ranges.

\section{Coping with variation in detection probability}

Of similar importance as knowing which factors influence the detection probability, is to know how to account for this variation in detection probability (Gjelland \& Hedger, 2013, 2017). Performing adaptations at the level of data analysis, mooring and receiver setup and/or research questions can partly overcome the problem. Changes to the setup or the questions to be answered can only be made if there is some a priori knowledge on the influencing factors. On many occasions, influences on detection probability only become clear once data analysis has started. This underlines the importance of reliable data analysis when dealing with the specific situation where the factors influencing the detection rate may bias the results towards false negatives (absences of recordings on specific moments despite fish being present). Data analysis should take this increased likelihood of false negatives into account. This can, for instance, be done by including a prevalence-adjusted performance criterion. Such a criterion contains an adjustable parameter that corrects for false negatives (Mouton et al., 2009a). The performance criterion can vary as a function of the influencing environmental parameters and thus allows incorporation of ecological relevance in the model optimisation process (Mouton et al., 2009b) to more accurately model the fish movement behaviour.

The present study revealed that current speed and azimuth influence the detection probability. This indicates that the mooring design could be improved. By fixing the receiver (e.g. on a frame), the hydrophone would not be able to tilt anymore. As a result, the 'line of sight' between receiver and transmitter would not change in function of the current direction. Although not empirically tested, this would probably reduce the statistical noise in the data.

Applicability of the range test setup

In Belgium, several short-term (i.e. hours up to a few days) range tests have previously been undertaken (but were never published) in both marine and freshwater environments. The current study is the first extensive range test in Belgian offshore waters and the setup used has, to our knowledge, never been used before. The research field of acoustic telemetry is characterised by fast technological improvements and new developments are launched regularly (Whoriskey \& Hindell, 2016). The VR2AR receivers used in this study are a relatively new type of receivers that combine a regular receiver with a built-in transmitter, an acoustic release and several sensors which monitor tilt angle, temperature, depth and noise (VEMCO, 2016b). There are several aspects that make such a type of receiver favourable for range testing. First, the transmission events from the built-in tag are logged in the memory of the receiver. They do not actually listen to their self-transmissions, but simply record the date and time that they transmitted, thus allowing the researcher to know the exact number of transmissions in a specific time period. This is a practical feature if the transmitters are programmed to send their signal in random delay modus or in situations where there is a high chance for echo detections due to the characteristics of the environment (e.g. in areas with hard substrates or ice cover). Secondly, the available sensors give in situ information on receiver tilt and an estimate of the presence of noise in the environment (VEMCO, 2016b). Although it does not give detailed information, these data can already inform researchers about possible environmental features conflicting with 
the transmissions. Further, with a limited number of units, many different distances between receiver and tags can be created, resulting in detailed information on the relation between detection probability and distance. Lastly, the built-in acoustic release allows for easy retrieval, without the need for surface marker buoys. This reduces complexity of the setup, and thus considerably reduces the chance of recovery failure of the mooring.

\section{Conclusions}

When interpreting acoustic telemetry data, it is important to keep in mind how the characteristics of sound propagation through water relate to environmental factors (i.e. meteorological, oceanographic and topographic) and interfere with other sound sources (both natural and human). It is important that scientists understand these influencing factors, consider their contribution and adjust for them where possible, when interpreting the results. We encourage performing range tests for each study area, and when possible, for the entire duration of a study. If the latter is not possible, the range test period should at least cover a time span that is sufficient to assess the influence of varying environmental conditions on detection probability.

The setup tested in this study made use of features (e.g. transmission event and tilt data) that render valuable information for data analysis and interpretation of the results. The setup is easy to deploy and retrieve. These aspects make it a comprehensive technique with potential for general applicability.

Acknowledgements P. Verhelst holds a doctoral grant from the Flemish Agency of Innovation \& Entrepreneurship (VLAIO). I. van der Knaap was granted by the PCAD4COD project. This research has benefitted from a statistical consult with Ghent University FIRE (Fostering Innovative Research based on Evidence). We thank the reviewers for their valuable input on the manuscript. We appreciated the constructive discussions concerning statistical model selection with Karl Gjelland, Gert Everaert and Jochen Depestele. Thanks to Stijn van Hoey from INBO for the help on the R-scripts. We thank Dries Van den Eynde from OD-Nature (Operational Directorate Natural Environment) for modelling the current data. Furthermore, this work was supported by data and infrastructure (RV Simon Stevin and RHIB Zeekat) provided by VLIZ as part of the Flemish contribution to LifeWatch. We would also like to thank Jean-Marie Beirens and Lieven Naudts from the Royal Belgian Institute of Natural Sciences,
Operational Directorate Natural Environment for infrastructure provision (RHIB Tuimelaar).

Open Access This article is distributed under the terms of the Creative Commons Attribution 4.0 International License (http:// creativecommons.org/licenses/by/4.0/), which permits unrestricted use, distribution, and reproduction in any medium, provided you give appropriate credit to the original author(s) and the source, provide a link to the Creative Commons license, and indicate if changes were made.

\section{References}

Abecasis, D., P. Afonso \& K. Erzini, 2014. Can small MPAs protect local populations of a coastal flatfish, Solea senegalensis? Fisheries Management and Ecology 21(3): 175-185.

Afonso, P., D. Abecasis, R. S. Santos \& J. Fontes, 2016. Contrasting movements and residency of two serranids in a small Macaronesian MPA. Fisheries Research 177: 59-70.

Baeye, M., M. Fettweis, G. Voulgaris \& V. Van Lancker, 2011. Sediment mobility in response to tidal and wind-driven flows along the Belgian inner shelf, southern North Sea. Ocean Dynamics 61(5): 611-622.

Berge, J., H. Capra, H. Pella, T. Steig, M. Ovidio, E. Bultel \& N. Lamouroux, 2012. Probability of detection and positioning error of a hydro acoustic telemetry system in a fast-flowing river: intrinsic and environmental determinants. Fisheries Research 125: 1-13.

Binder, T. R., C. M. Holbrook, T. A. Hayden \& C. C. Krueger, 2016. Spatial and temporal variation in positioning probability of acoustic telemetry arrays: fine-scale variability and complex interactions. Animal Biotelemetry 4(1): 4.

Cagua, E. F., M. L. Berumen \& E. Tyler, 2013. Topography and biological noise determine acoustic detectability on coral reefs. Coral Reefs 32(4): 1123-1134.

Clements, S., D. Jepsen, M. Karnowski \& C. B. Schreck, 2005. Optimization of an acoustic telemetry array for detecting transmitter-implanted fish. North American Journal of Fisheries Management 25(2): 429-436.

Dance, M. A., D. L. Moulton, N. B. Furey \& J. R. Rooker, 2016. Does transmitter placement or species affect detection efficiency of tagged animals in biotelemetry research? Fisheries Research 183: 80-85.

De Jong, C., M. Ainslie \& G. Blacquière, 2011. Standard for measurement and monitoring of underwater noise, Part II: procedures for measuring underwater noise in connection with offshore wind farm licensing. Report no TNODV:C251.

Dol, H. S., M. Colin, M. A. Ainslie, P. A. van Walree \& J. Janmaat, 2013. Simulation of an underwater acoustic communication channel characterized by wind-generated surface waves and bubbles. IEEE Journal of Oceanic Engineering 38(4): 642-654.

Dormann, C. F., J. Elith, S. Bacher, C. Buchmann, G. Carl, G. Carré, J. R. G. Marquéz, B. Gruber, B. Lafourcade \& P. J. Leitão, 2013. Collinearity: a review of methods to deal 
with it and a simulation study evaluating their performance. Ecography 36(1): 27-46.

Douvere, F., F. Maes, A. Vanhulle \& J. Schrijvers, 2007. The role of marine spatial planning in sea use management: the Belgian case. Marine Policy 31(2): 182-191.

Fettweis, M., J. Monbaliu, M. Baeye, B. Nechad \& D. Van den Eynde, 2012. Weather and climate induced spatial variability of surface suspended particulate matter concentration in the North Sea and the English Channel. Methods in Oceanography 3: 25-39.

Forstmeier, W. \& H. Schielzeth, 2011. Cryptic multiple hypotheses testing in linear models: overestimated effect sizes and the winner's curse. Behavioral Ecology and Sociobiology 65(1): 47-55.

Gjelland, K. Ø. \& R. D. Hedger, 2013. Environmental influence on transmitter detection probability in biotelemetry: developing a general model of acoustic transmission. Methods in Ecology and Evolution 4(7): 665-674.

Gjelland, K. Ø. \& R. D. Hedger, 2017. On the parameterization of acoustic detection probability models. Methods in Ecology and Evolution 8(10): 1302-1304.

Hayden, T. A., C. M. Holbrook, T. R. Binder, J. M. Dettmers, S. J. Cooke, C. S. Vandergoot \& C. C. Krueger, 2016. Probability of acoustic transmitter detections by receiver lines in Lake Huron: results of multi-year field tests and simulations. Animal Biotelemetry 4(1): 19.

Hegyi, G. \& L. Z. Garamszegi, 2011. Using information theory as a substitute for stepwise regression in ecology and behavior. Behavioral Ecology and Sociobiology 65(1): 69-76.

Heupel, M. R., J. M. Semmens \& A. J. Hobday, 2006. Automated acoustic tracking of aquatic animals: scales, design and deployment of listening station arrays. Marine and Freshwater Research 57(1): 1-13.

Hobday, A. J. \& D. Pincock, 2011. Estimating detection probabilities for linear acoustic monitoring arrays. In American Fisheries Society Symposium, Vol. 76: 1-22.

How, J. R. \& S. de Lestang, 2012. Acoustic tracking: issues affecting design, analysis and interpretation of data from movement studies. Marine and Freshwater Research 63(4): 312-324.

Hussey, N. E., K. J. Hedges, A. N. Barkley, M. A. Treble, I. Peklova, D. M. Webber, S. H. Ferguson, D. J. Yurkowski, S. T. Kessel \& J. M. Bedard, 2017. Movements of a deepwater fish: establishing marine fisheries management boundaries in coastal Arctic fisheries. Ecological Applications 27(3): 687-704.

Huveneers, C., C. A. Simpfendorfer, S. Kim, J. M. Semmens, A. J. Hobday, H. Pederson, T. Stieglitz, R. Vallee, D. Webber, M. R. Heupel, V. Peddemors \& R. G. Harcourt, 2016. The influence of environmental parameters on the performance and detection range of acoustic receivers. Methods in Ecology and Evolution 7(7): 825-835.

Jensen, F., W. Kuperman, M. Porter \& H. Schmidt, 1994. Computational Ocean Acoustics. Springer, Berlin.

Kessel, S. T., S. J. Cooke, M. R. Heupel, N. E. Hussey, C. A. Simpfendorfer, S. Vagle \& A. T. Fisk, 2014. A review of detection range testing in aquatic passive acoustic telemetry studies. Reviews in Fish Biology and Fisheries 24(1): 199-218.
Kessel, S. T., N. E. Hussey, D. M. Webber, S. H. Gruber, J. M. Young, M. J. Smale \& A. T. Fisk, 2015. Close proximity detection interference with acoustic telemetry: the importance of considering tag power output in low ambient noise environments. Animal Biotelemetry 3(1): 5.

Martin, B., C. Whitt, C. Mcpherson, A. Gerber \& M. Scotney, 2013. Measurement of long-term ambient noise and tidal turbine levels in the Bay of Fundy. In: Nova Scotia Tidal Energy Research Symposium \& Forum: 26.

Medwin, H. \& C. S. Clay, 1998. Fundamentals of Acoustical Oceanography. Academic Press, Boston.

Mouton, A. M., B. De Baets, E. Van Broekhoven \& P. L. M. Goethals, 2009a. Prevalence-adjusted optimisation of fuzzy models for species distribution. Ecological Modelling 220: 1776-1786.

Mouton, A. M., I. Jowett, P. L. M. Goethals \& B. De Baets, 2009b. Prevalence-adjusted optimisation of fuzzy habitat suitability models for aquatic invertebrate and fish species in New Zealand. Ecological Informatics 4: 215-225.

Otto, L., J. T. F. Zimmerman, G. K. Furnes, M. Mork, R. Saetre \& G. Becker, 1990. Review of the physical oceanography of the North Sea. Netherlands Journal of Sea Research 26: 161-238.

R Core Team, 2016. R: A language and environment for statistical computing. Vienna: R Foundation for Statistical Computing. http://www.R-project.org/.

Reubens, J., M. De Rijcke, S. Degraer \& M. Vincx, 2014. Diel variation in feeding and activity patterns of juvenile Atlantic cod at offshore wind farms. Journal of Sea Research 85: 214-221.

Selby, T. H., K. M. Hart, I. Fujisaki, B. J. Smith, C. J. Pollock, Z. Hillis-Starr, I. Lundgren \& M. K. Oli, 2016. Can you hear me now? Range-testing a submerged passive acoustic receiver array in a Caribbean coral reef habitat. Ecology and Evolution 6(14): 4823-4835.

Simpfendorfer, C. A., M. R. N. Heupel \& A. B. Collins, 2008. Variation in the performance of acoustic receivers and its implication for positioning algorithms in a riverine setting. Canadian Journal of Fisheries and Aquatic Sciences 65(3): 482-492.

Steckenreuter, A., X. Hoenner, C. Huveneers, C. Simpfendorfer, M. J. Buscot, K. Tattersall, R. Babcock, M. Heupel, M. Meekan \& J. van den Broek, 2016. Optimising the design of large-scale acoustic telemetry curtains. Marine and Freshwater Research 68(8): 1403-1413.

Stocks, J. R., C. A. Gray \& M. D. Taylor, 2014. Testing the effects of near-shore environmental variables on acoustic detections: implications on telemetry array design and data interpretation. Marine Technology Society Journal 48: 28-35.

Vemco, 2015. Receiver Noise Measurements. https://vemco. com/wp-content/uploads/2015/05/receiver-noise.pdf

Vemco, 2016a. VR2AR Deployment Tips. https://vemco.com/ wp-content/uploads/2015/01/vr2ar-deploy-tips.pdf

Vemco, 2016b. VR2AR User Manual. https://vemco.com/wpcontent/uploads/2015/01/vr2ar-manual.pdf

Welsh, J. Q., R. J. Fox, D. M. Webber \& D. R. Bellwood, 2012. Performance of remote acoustic receivers within a coral reef habitat: implications for array design. Coral Reefs 31(3): 693-702. 
Whoriskey, F. \& M. Hindell, 2016. Developments in tagging technology and their contributions to the protection of marine species at risk. Ocean Development and International Law 47(3): 221-232.

Winter, H. V., G. Aarts \& O. A. van Keeken, 2010. Residence time and behaviour of sole and cod in the Offshore Wind farm Egmond aan Zee (OWEZ). IMARES, Wageningen YR report number: $\mathrm{C} 038 / 10,50 \mathrm{pp}$.
Zuur, A., E. Ieno, N. Walker, A. Saveliev \& G. Smith, 2009. Mixed Effects Models and Extensions in Ecology with R. Springer.

Zuur, A. F., E. N. Ieno \& C. S. Elphick, 2010. A protocol for data exploration to avoid common statistical problems. Methods in Ecology and Evolution 1(1): 3-14. 